\title{
The elusive mass in the right atrium: A liver in the heart
}

\author{
Tsuyoshi Kaneko, MD, and Sary F. Aranki, MD
}

\author{
From the Division of Cardiac Surgery, Brigham and Women's Hospital, Boston, Mass. \\ Disclosures: Authors have nothing to disclose with regard to commercial support. \\ Received for publication Sept 13, 2017; accepted for publication Sept 15, 2017; available ahead of print Nov 10 , \\ 2017. \\ Address for reprints: Sary F. Aranki, MD, Division of Cardiac Surgery, Brigham and Women's Hospital, 75 Fran- \\ cis St, Boston, MA 02115 (E-mail: saranki@partners.org). \\ J Thorac Cardiovasc Surg 2018;155:e49-50 \\ $0022-5223 / \$ 36.00$ \\ Copyright (C 2017 by The American Association for Thoracic Surgery \\ https://doi.org/10.1016/j.jtcvs.2017.09.099
}

Intracardiac or caval heterotopic liver tissue is a rare condition, and only a few cases have been reported in the literature. In this edition of the Journal, Giritharan and associates $^{1}$ report a case of intracaval heterotopic liver tissue that was successfully resected. Only 6 cases of intracardiac or caval masses, of a total of 120 cases of heterotopic liver tissue, have been reported in the literature.

In this case, the patient's magnetic resonance imaging (MRI) showed a mass with attachment in the inferior vena cava (IVC) extending into the right atrium with low to intermediate $\mathrm{T} 1$ and $\mathrm{T} 2$ signals, indicating that the tissue was similar to myocardium. The tumor was resected through a median sternotomy with the use of mild hypothermic $\left(32^{\circ} \mathrm{C}\right)$ cardiopulmonary bypass. Superior vena cava and femoral venous cannulations were used for venous drainage. After cardiac arrest and through a right atriotomy, the mass was identified and the stalk cauterized. The histologic examination showed a polypoid mass with normal liver parenchyma.

This case report highlights 2 issues that are of extreme importance in the diagnosis and treatment of a right atrial mass: state-of-the-art MRI imaging and the optimal surgical strategy (Figure 1 ). ${ }^{2}$ A cardiac MRI scan provides information about the localization, anatomy, and tissue characterization features of a right atrial mass that make excluding what it is not as important as determining what it actually is. Anatomically, in the presence of a stalk, a thrombus that is usually layered against the wall of the right atrium will be excluded. Similarly, a primary or secondary malignant neoplasm can be excluded in the absence of atrial wall invasion. A heterogeneous pedunculated characterization of the mass would most certainly indicate an atrial myxoma, and less likely a thrombus, a metastatic tumor, or a primary cardiac tumor. In this particular case, the tumor had a stalk with the point of attachment in the IVC. The mass was homogeneous and not pedunculated, with no significant early or late gadolinium enhancement, and it had low intermediate T1 and T2 signals similar to myocardium. These characteristics pretty much exclude primary or secondary cardiac from the MRI.

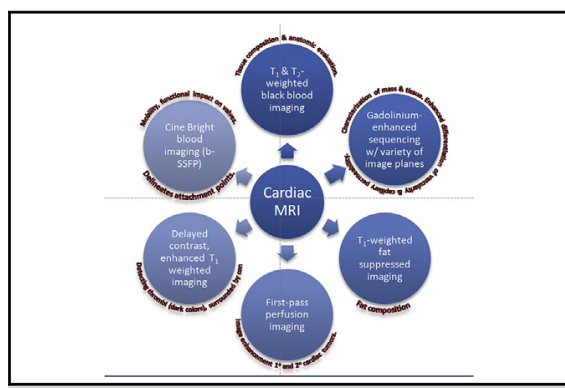

State-of-the-art cardiac MRI for cardiac tumor with different imaging.

\section{Central Message}

Intracardiac heterotopic liver tissue is a rare condition. Localization and tissue composition and characterization can be ascertained with cardiac MRI. We recommend resection with CPB and DHCA.

See Article page e47.

tumors, including myxoma and thrombus. The presence of a transvenous extension from the IVC raises the suspicion of renal or hepatocellular tumors, but these could be excluded

The surgical principle of resecting a mass in the right atrium would be cardiopulmonary bypass, with a total bloodless field and the right atrium. This is usually achieved by cannulating the superior vena cava and the IVC and snaring the vessels around the cannulas. In the presence of an extension or attachment in the IVC, however, achieving a bloodless field for optimal visualization would be difficult. In this situation, cannulation of the common femoral vein with a long cannula, positioning the tip just below the level of the tumor, would be recommended. Because the extent of the caval attachment is difficult to ascertain before the procedure, it is highly recommended that deep hypothermia and low-flow or total circulatory arrest be used. The strategy allows a total bloodless field, direct visualization of the attachment of the tumor, safe resection from the caval insertion, and repair of any IVC defects that may result. It may also be wise to have a liver surgeon on standby, in case an intra-abdominal repair of the IVC is required. Giritharan and associates ${ }^{1}$ were extremely lucky in not encountering any serious complications in this case. The attachment of the mass was deeper in the IVC, just above the level of the portal veins. The cardiopulmonary bypass flow was intermittently reduced for better visualization, and the stalk was pulled and amputated close to 


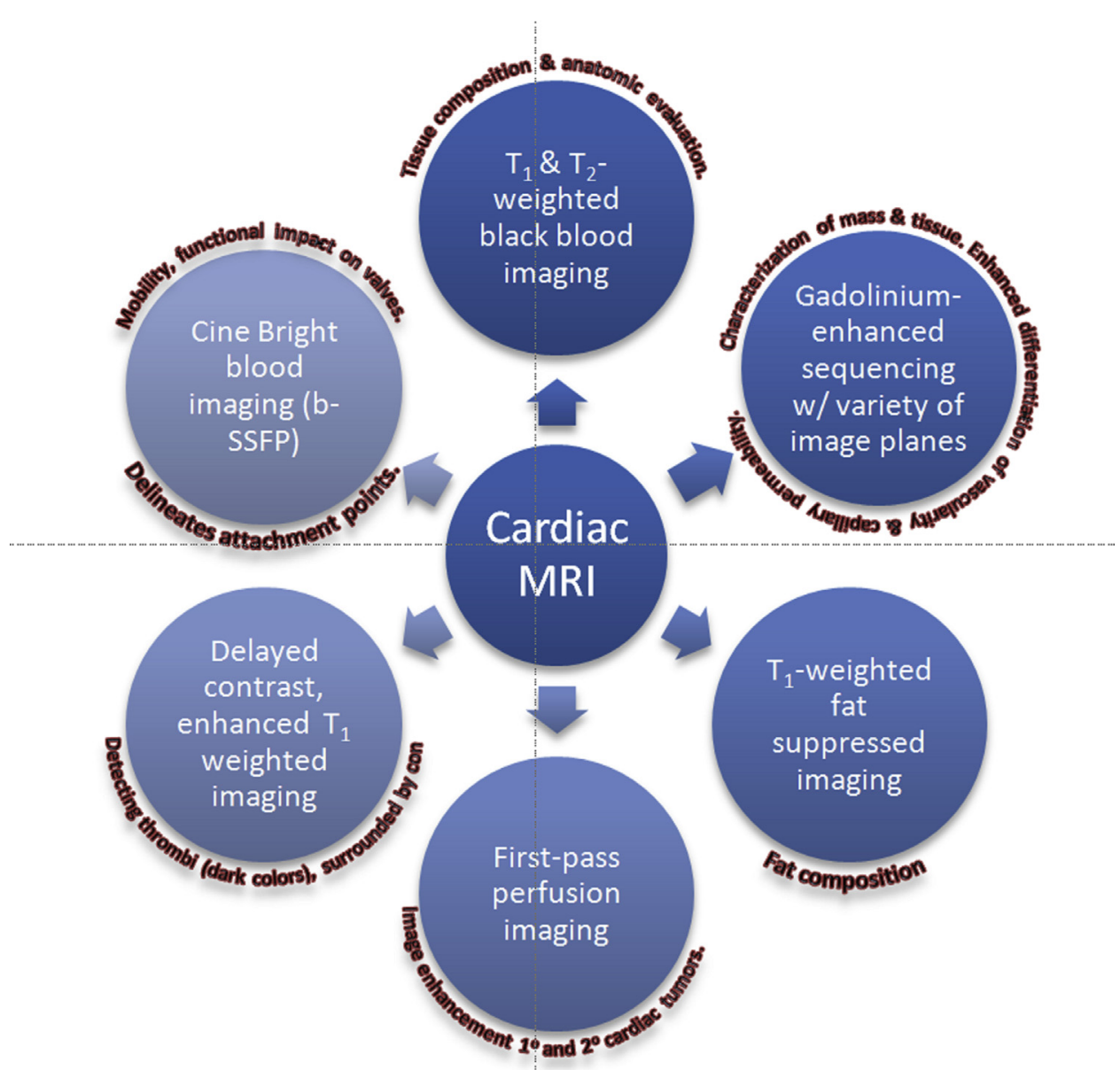

FIGURE 1. State-of-the-art cardiac magnetic resonance imaging $(M R I)$ for cardiac tumor with different imaging modalities. $b$-SSFP, Balanced steady-state free precession.

its base. Luckily, no complications occurred; had any done so, a straightforward operation would have become a disastrous one, with unknown serious complications and outcomes.

\section{References}

1. Giritharan S, Salhiyyah K, Tsang G. Surgical excision of ectopic hepatic tissue in the right atrium. J Thorac Cardiovasc Surg. 2018;155:e47-8.

2. Attili AK, Gebker R, Cascade PN. Radiological reasoning: right atrial mass. AJR Am J Roentgenol. 2007;188(6 Suppl):S26-30. 